\title{
A network pharmacology-based study on the anti-hepatoma effect of Radix Salviae Miltiorrhizae
}

\author{
Yi Luo', Yu Feng ${ }^{2,3}$, Lei Song ${ }^{1}$, Gan-Qing He ${ }^{4}$, Sha Li ${ }^{5}$, Sha-Sha Bai ${ }^{1}$, Yu-Jie Huang ${ }^{1}$, Si-Ying Li ${ }^{6}$, \\ Mohammed M. Almutairi ${ }^{6}$, Hong-Lian Shi $^{6}$, Qi Wang ${ }^{1 *}$ and Ming Hong ${ }^{1 *}$
}

\begin{abstract}
Background: Radix Salviae Miltiorrhizae (RSM), a well-known traditional Chinese medicine, has been shown to inhibit tumorigenesis in various human cancers. However, the anticancer effects of RSM on human hepatocellular carcinoma (HCC) and the underlying mechanisms of action remain to be fully elucidated.

Methods: In this study, we aimed to elucidate the underlying molecular mechanisms of RSM in the treatment of HCC using a network pharmacology approach. In vivo and in vitro experiments were also performed to validate the therapeutic effects of RSM on HCC.

Results: In total, 62 active compounds from RSM and 72 HCC-related targets were identified through network pharmacological analysis. RSM was found to play a critical role in HCC via multiple targets and pathways, especially the EGFR and PI3K/AKT signaling pathways. In addition, RSM was found to suppress HCC cell proliferation, and impair cancer cell migration and invasion in vitro. Flow cytometry analysis revealed that RSM induced cell cycle G2/M arrest and apoptosis, and western blot analysis showed that RSM up-regulated the expression of BAX and down-regulated the expression of $\mathrm{BCl}-2$ in MHCC97-H and HepG2 cells. Furthermore, RSM administration down-regulated the expression of EGFR, PI3K, and p-AKT proteins, whereas the total AKT level was not altered. Finally, the results of our in vivo experiments confirmed the therapeutic effects of RSM on HCC in nude mice.
\end{abstract}

Conclusions: We provide an integrative network pharmacology approach, in combination with in vitro and in vivo experiments, to illustrate the underlying therapeutic mechanisms of RSM action on HCC.

Keywords: Radix Salviae Miltiorrhizae, Hepatocellular carcinoma, Network pharmacology

\section{Background}

Hepatocellular carcinoma (HCC) is the most frequent primary liver malignancy and is a major health problem worldwide [1]. In 2017, 782,000 cases were diagnosed and there were 746,000 deaths, and the incidence of HCC in worldwide continued to increase, with an age-adjusted incidence rising 10 per 100,000 individuals [2]. Chronic liver disease and cirrhosis remain the most significant risk factors for the development of HCC, of which hepatitis virus infection and excessive alcohol intake are the

\footnotetext{
*Correspondence: wangqi2234@163.com; hongming2234@163.com 1 Institute of Clinical Pharmacology, Guangzhou University of Chinese Medicine, Guangzhou 510405, China

Full list of author information is available at the end of the article
}

leading risk factors worldwide [3-5]. As patients in the early stages of HCC are generally asymptomatic, it is mainly diagnosed at an advanced stage, when the condition is incurable. While current treatment regimens have increased survival time for patients, the utilization of sorafenib has only increased survival by a few months [6]. In addition, sorafenib is associated with severe sideeffects, which have limited the clinical use of the drug. Hence, new medicines with good efficacy and tolerability are urgently demanded.

In recent years, researchers have focused on developing a Traditional Chinese Medicine (TCM) for the treatment of HCC. Radix Salviae Miltiorrhizae (RSM), also known as Danshen in Chinese, is a widely used Chinese medicine, 
which has been applied clinically for more than 1000 years. Research has shown that RSM possesses a variety of pharmacological effects, including anti-platelet aggregation, anti-hypertension, anti-inflammation, and improvement of cerebral ischemia reperfusion injury, as well as cardiovascular protection [7-10]. Evidence accumulated in the last decade has demonstrated that RSM also demonstrates a significant anti-cancer effect against breast cancer, clear cell ovarian carcinomas, promyelocytic leukemia, and HCC [11-13]. Bae et al. [14] showed that S. miltiorrhiza Bunge might present a significant anticancer effect by inhibiting prostate cancer cell proliferation and inducing prostate cancer cell apoptosis. Kim et al. [15] revealed that S. miltiorrhiza extracts inhibited TPA-induced MCF-7 cell invasion and Matrix metalloproteinase-2 (MMP-9) expression by blocking the transcriptional activation of AP-1. The main active ingredients in Radix S. miltiorrhizae can be classified into two parts: hydrosoluble salvianolic acids (salvianolic acid A, salvianolic acid B, danshensu, rosmarinic acid) and liposoluble tanshinones (tanshinone IIA [TIIA], cryptotanshinone [CT], dihydrotanshinone I [DH-TI], tanshinone I [TI]). Previous studies have shown that TIIA is an active component of RSM, which inhibits human gastric cancer cells by decreasing HER2 and VEGFR protein levels, inhibits the Ras/Raf/MEK/ERK signaling pathway, and induces caspase-3, PARP activation, and apoptosis [16]. TIIA also decreases human cancer cell invasion and metastasis in the nude mice model. In addition, salvianolic acid B induces autophagy and exerts antitumor effects in colorectal cancer cells via inhibition of the AKT/mTOR pathway [17]. RSM and its active components may serve as a promising anti-cancer therapy; however, its pharmacological mechanisms of action have not been fully elucidated. Therefore, the aim of our research was to explore the anti-HCC effects of RSM extracts and explore the underlying mechanisms.

TCM is typically associated with multiple targets, multiple pathways, and multiple mechanisms of actions, making it difficult to elucidate its effects. These greatly restrict the process of modernization and internationalization of Chinese medicine. The concept of network pharmacology derived from the introduction of systems biology and the application of bioinformatics, along with "omics" theory involved in modern genomic, proteomic, and metabolomic development. Network pharmacology was developed based on the rapid development of systems biology and computer technology. Based on the "disease-gene-targetdrug" interaction network, network analysis was used to observe the intervention and influence of drugs on the disease network, and the synergistic effects of multiple drugs were determined $[18,19]$. In recent years, network pharmacology has emerged as a powerful tool that can be integrated with pharmacology. It provides a novel tool and concept to evaluate the efficacy mechanisms of action of drugs. Combining the target database of TCM in various diseases with molecular verification provides evidence for the molecular target and its mechanism of action [20-23]. Thus, this study combines network pharmacology with experimental validation to clarify the potential mechanism of RSM against $\mathrm{HCC}$ and suggests a novel promising therapeutic strategy for the treatment of HCC (Fig. 1).

\section{Methods}

The Minimum Standards of Reporting Checklist contains details of the experimental design, statistics, and resources used in this study.

\section{Compound database building}

Traditional Chinese Medicine Systems Pharmacology (TCMSP) is a unique system pharmacology platform of Chinese herbal medicines, which captures the relationships between drugs, targets, and diseases. A catalog of chemical ingredients was generated from related articles and the natural products database of TCMSP (http://lsp. nwu.edu.cn/tcmsp.php) [24].

\section{Pharmacokinetic prediction}

Absorption, distribution, metabolism, and excretion (ADME), an in silico evaluation model in pharmacokinetic research, was employed to select drugs. In this study, an in silico ADME-systems evaluation model including drug-likeness (DL) and oral bioavailability $(\mathrm{OB})$ was applied to evaluate the potential bioactive components of RSM. OB is an essential parameter of orally administered drugs, and is used to assess the pharmacokinetics and drug-forming properties of drugs in vivo. The TCMSP database calculated OB values using OBioavail1.1 [25]. Drug-likeness (DL) is a qualitative concept used in drug design to evaluate how "drug-like" a molecule is with respect to factors such as bioavailability. $\mathrm{DL}$ is estimated from the molecular structure before the substance is synthesized and tested. To identify drug-like ingredients, the Tanimoto coefficient, $T(A, B)=(A \times B) /$ $(|A| 2+|B| 2-A \times B)$ was applied to calculate the DL values of each ingredient in RSM by a database-dependent model. A presents the new compound, and B displays the average molecular properties of all compounds in the DrugBank database (http://www.drugbank.ca). In this study, molecules with $\mathrm{DL} \geq 0.18, \mathrm{OB} \geq 30 \%$ were used for subsequent research, and others were excluded.

\section{Compound targets for RSM}

A systematic drug targeting tool was used to predict the targets of candidate molecules, which efficiently combines genomic, chemical, and pharmacological 


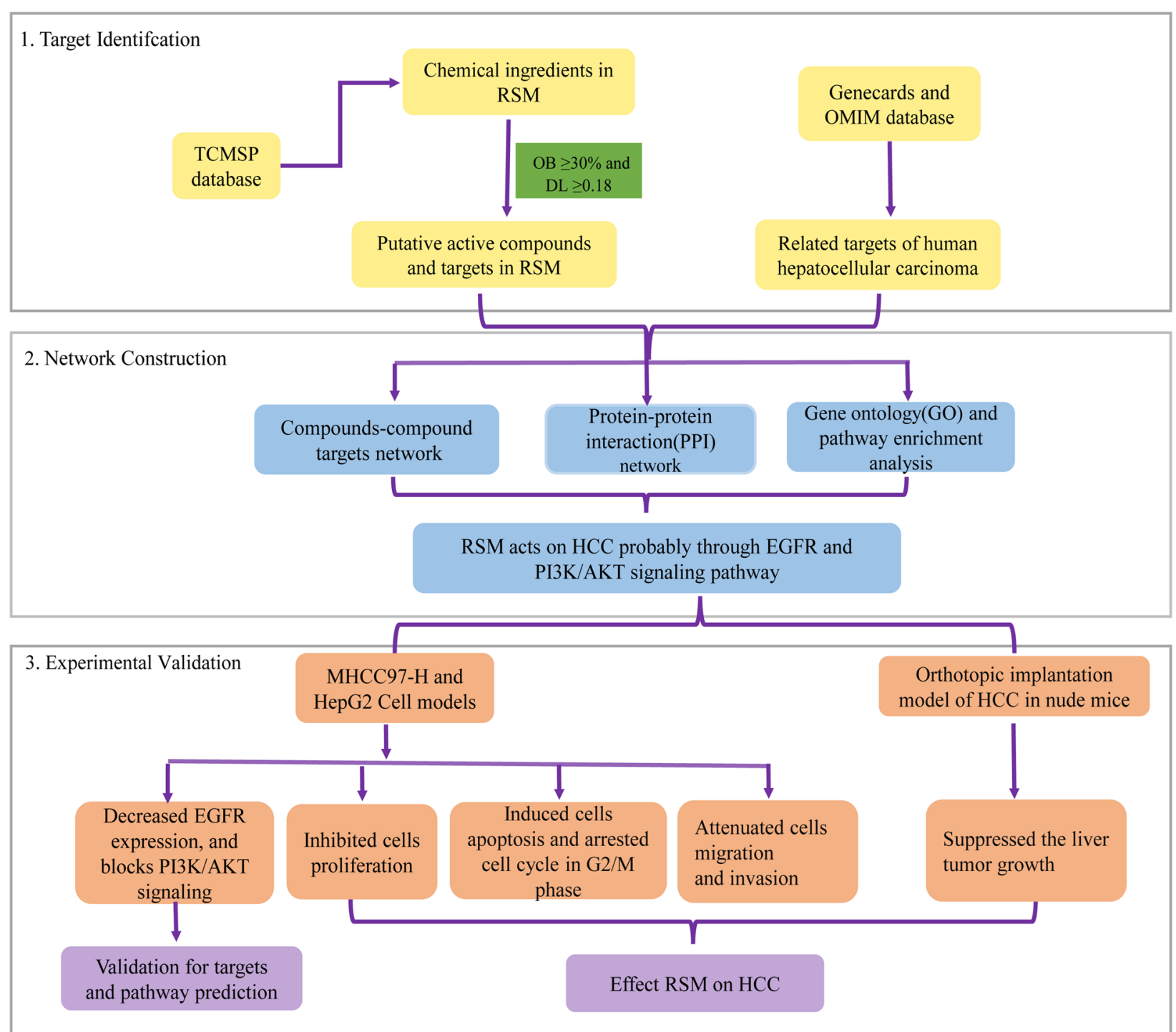

Fig. 1 Flowchart showing the systems pharmacology approach for determining the pharmacological mechanisms of action of Radix Salviae Miltiorrhizae (RSM) on human hepatocellular carcinoma (HCC) by integrating target identification, network analysis, and experimental validation

information for drug targeting through Random Forest (RF) and Support Vector Machine (SVM) methods [26]. In this study, compound-target interactions with a RF score $\geq 0.7$ and an SVM score $\geq 0.8$ were regarded as potential targets for active molecules.

\section{Related targets of $\mathrm{HCC}$}

HCC-related genes were collected from two databases. 1. GeneCards (http://www.genecards.org) [27] is a searchable, integrative database of human genes that provides genomic, proteomic, transcriptomic, genetic, and functional information on all known and predicted human genes. The database automatically integrates gene-centric data from $~ 125$ web sources, such as HGNC, NBCI, and Ensemble. 2. Online Mendelian Inheritance in Man (OMIM) (http://omim.org/) [28] is a comprehensive, authoritative compendium of human genes and genetic phenotypes, which is freely available and updated daily. We searched these databases with the keywords "hepatocellular carcinoma" and "hepatocarcinoma".

\section{Construction of a protein-protein interaction (PPI) network} PPI data were derived from String (http://string-db.org/, ver.10) [29], an online database of known and predicted protein-protein interactions with the species limited to "Homo sapiens" and a confidence score $>0.4$. 


\section{Gene ontology (GO) and pathway enrichment analysis}

The Database for Annotation, Visualization, and Integrated Discovery (DAVID; http://david.abcc.ncifcrf.gov/) $[30,31]$ was employed in GO and Kyoto Encyclopedia of Genes and Genomes (KEGG) pathway enrichment analysis.

\section{Network construction}

The network was constructed as follows: (1) compoundcompound target network of RSM; (2) PPI network. All visualized networks were constructed using software Cytoscape (http://cytoscape.org/, ver. 3.6.0), an open software platform for visualizing biological pathways, molecular interaction networks, and integrating these networks with annotations, gene expression profiles, and other state data.

\section{Reagents and antibodies}

Fetal bovine serum (FBS), Dulbecco's modified Eagle's medium (DMEM), and penicillin-streptomycin were provided from Gibco. Cell culture supplies were obtained from Costar (Corning, USA). Antibodies, including antiPI3-kinase p85- $\alpha$ (ab182651), anti-Bcl-2 (ab59348), HRPconjugated goat anti-rabbit (ab6721), and anti-mouse IgG (ab6789) were from Abcam (Cambridge, UK). Antibodies, including anti-EGFR (\#4267), anti-Bax (\#2772), antiAKT (\#9272), anti-p-AKT (\#4058), and $\beta$-actin (ab8227) were obtained from Cell Signaling Technology (Boston, USA).

\section{Preparation of ethanol extract from RSM}

Dried roots of. S. miltiorrhiza Bunge were obtained from Xing Yuan Chun Pharmacy (Guangzhou, China). The original herb was identified by the Department of Traditional Chinese Medicine, Guangzhou University of Traditional Chinese Medicine, China. A voucher specimen was deposited at the public Herbarium of the Department of Traditional Chinese Medicine, Guangzhou University of Traditional Chinese Medicine. Samples (500 g) of dried roots of $S$. miltiorrhiza Bunge were extracted with $5 \mathrm{~L}$ of $95 \%$ ethanol using a refluxing method and then filtered. The filtrates were evaporated and lyophilized to obtain a dried powder. Dried powder obtained from the ethanol extracts of RSM was stored in $4{ }^{\circ} \mathrm{C}$ for future use.

\section{HPLC analysis}

Ethanol extracts of Radix S. miltiorrhizae were qualitatively analyzed by high-performance liquid chromatography (HPLC). Shimadzu HPLC systems (LC-20AT, Japan), equipped with a CM-20A system controller, an infusion pump (LC-20A, Japan), an automatic sampler (Sil-20A, Japan), and a CTO-20A column temperature chamber, were used for chromatographic analysis. Ethanol extracts of Radix S. miltiorrhizae, TIIA, TI, CT, and DH-TI were separated on WondaSil C18-WR $(250 \mathrm{~mm} \times 4.6 \mathrm{~mm}$, $5 \mu \mathrm{m})$ at $30{ }^{\circ} \mathrm{C}$. The sample was eluted at a flow rate of $1 \mathrm{~mL} / \mathrm{min}$ in a gradient elution program of A (acetonitrile) and B (water): 0-0.01 min (42\% B); 0.01-25 min (10\% B); $25-27 \min (42 \% \mathrm{~B}) ; 27-35 \mathrm{~min}$ (42\% B). The injection volume was $20 \mu \mathrm{L}$. Monitoring was performed at $270 \mathrm{~nm}$ with an SPD-M20A diode array detector. TIIA, TI, CT, and DH-TI.

\section{Cell lines and culture}

Human HCC cell lines MHCC97-H and HepG2 were obtained from the Chinese Academy of Sciences cell bank, Beijing, China. Cells were cultured in DMEM/high glucose medium with $10 \% \mathrm{FBS}$ and $100 \mathrm{U} / \mathrm{mL}$ penicillin-streptomycin, and incubated at $37{ }^{\circ} \mathrm{C}$ in a $5 \% \mathrm{CO}_{2}$ incubator.

\section{Cell viability assay}

Cells were seeded into a 96-well plate at a density of $1 \times 10^{5} / \mathrm{mL}(100 \mu \mathrm{L} /$ well $)$ and cultured overnight. Cell viability was evaluated by MTT $(5 \mathrm{mg} / \mathrm{mL})$ at $24 \mathrm{~h}$. Following the addition of $10 \mu \mathrm{L}$ MTT per well, cells were incubated for $4 \mathrm{~h}$ at $37{ }^{\circ} \mathrm{C}$. The medium was removed, and $150 \mu \mathrm{L}$ of dimethyl sulfoxide (DMSO) was added to each well. The optical density (OD) value was detected at the wavelength of $490 \mathrm{~nm}$ using a microplate reader (Thermo Fisher, USA) after thoroughly shaking the plate.

\section{Colony formation assay}

One-thousand cells were seeded in a six-well plate and cultured in DMEM containing 10\% FBS. The culture medium was replaced every 3 days. After 14 days, the colonies were fixed with $4 \%$ paraformaldehyde for 10-15 min and stained with crystal violet solution for $10 \mathrm{~min}$. Cell colonies in each well that had $\geq 50$ cells per colony were counted after washing with water.

\section{Wound-healing assay}

MHCC97-H and HepG2 cells $\left(4 \times 10^{5}\right.$ cells/well) were seeded in a 6-well plate for use in wound-healing assays. After the cells reached full confluence, the cell monolayer was scratched using a $10 \mu \mathrm{L}$ pipette tip and the medium was replaced with medium containing $0.1 \%$ FBS. The scratches were imaged at 0 and $48 \mathrm{~h}$ following scratching, using a $10 \times$ objective microscope. The cell migration rate was calculated as the distance of the wound recovered versus that of the original wound.

\section{Transwell migration and invasion assay}

A Transwell invasion and migration assay was performed to determine cell migration and invasion capacities. Cells 
$\left(2 \times 10^{5}\right)$ in serum-free medium were seeded onto the upper chamber after drug treatment, and the bottom chamber was placed into DMEM medium containing $10 \%$ FBS. After $24 \mathrm{~h}$ incubation, cells on the upper surface of the membrane were removed and the invading cells were fixed in $4 \%$ paraformaldehyde for $10 \mathrm{~min}$ and stained with crystal violet solution for $5 \mathrm{~min}$. A cell invasion assay was performed similarly, except that $60 \mu \mathrm{L}$ of Matrigel (BD Biosciences, USA) diluted 1:8 with serumfree medium, was added to each well overnight before the cells were seeded onto the membrane. The number of invading cells was analyzed statistically using three independent experiments and the results were averaged from five image fields.

\section{Flow cytometry for cell cycle analysis}

MHCC 97-H and HepG2 cells were harvested by trypsinization following treatment with $\operatorname{RSM}(0,5,10$, and $20 \mu \mathrm{g} /$ $\mathrm{ml}$ ) for $24 \mathrm{~h}$. Cells were fixed in $70 \%$ cold ethanol at $4{ }^{\circ} \mathrm{C}$ overnight after washing twice in cold PBS. Then, the cells were washed twice with cold PBS, centrifuged at $1000 \mathrm{~g}$ for 3-5 min to precipitate cells and then treated with $500 \mu \mathrm{L}$ staining buffer (PI/RNase $\mathrm{A}=9: 1)$ at $37{ }^{\circ} \mathrm{C}$ for $40 \mathrm{~min}$ in the dark. A flow cytometer was used to analyze the samples and the results were analyzed using Modifit acquisition software.

\section{Flow cytometry for analysis of cell apoptosis}

Apoptosis was analyzed using an Annexin V-FITC apoptosis detection kit (Vazyme, China). MHCC97-H and HepG2 cells were seeded at a density of $10^{6}$ cells/well in 6-well plates. After $24 \mathrm{~h}$ treatment with RSM, the cells were analyzed using an Annexin V-FITC kit to detect apoptosis. The apoptotic cells were detected by flow cytometry (BD Biosciences, USA).

\section{Western blot}

Cell proteins were extracted after $24 \mathrm{~h}$ incubation with the indicated concentrations of RSM. The cells were homogenized and lysed in sample buffer $(0.5 \mathrm{M}$ Tris/ $\mathrm{HCl} \mathrm{pH} \mathrm{6.8,} \mathrm{50 \%} \mathrm{glycerol,} 10 \%$ sodium dodecyl sulphate [SDS], 1: 100 protease and phosphatase inhibitor cocktail). Total cell lysates were separated by $10 \%$ sodium dodecyl sulfate polyacrylamide gel electrophoresis (SDS-PAGE) and $t$ transferred onto polyvinylidene difluoride (PVDF) membranes (Bio-Rad, USA). Then, the membranes were blocked with $5 \%$ bovine serum albu$\mathrm{min}$ for $2 \mathrm{~h}$ at room temperature and incubated with the appropriate primary antibody solution including EFGR (1:1000), anti-PI3-kinase p85- $\alpha$ (1:1000), anti-Bcl-2 (1:1000), anti-Bax (1:1000), anti-AKT (1:1000), anti-pAKT (1:1000), and $\beta$-actin $(1: 8000)$ overnight at $4{ }^{\circ} \mathrm{C}$. The membranes were incubated with HRP-conjugated goat anti-mouse or anti-rabbit IgG (1:1000) for $2 \mathrm{~h}$ at room temperature and the protein bands were visualized by an ECL kit.

\section{Orthotopic transplantation of $\mathrm{HCC}$ in nude mice}

Five-week-old BALB/c male nude mice were obtained from the Experimental Animal Center of Guangzhou University of Traditional Chinese Medicine. MHCC97L-luciferase cells $\left(5 \times 10^{6} / 100 \mu \mathrm{L}\right)$ were subcutaneously injected into the nude mice. Once it reached a diameter of $1 \mathrm{~cm}$, the subcutaneous tumor was cut into approximately $1 \mathrm{~mm}^{3}$ pieces and implanted into the left liver lobes of another group of nude mice. Mice with luciferase signals from liver HCC tumors were analyzed by Xenogen IVIS after 7 days. Surviving mice, with successfully implanted tumors confirmed by in vivo imaging (Xenogen Corp. USA), were randomly divided into three groups: a control saline group $(n=5)$, an RSM low dose group ( $\mathrm{n}=5,100 \mathrm{mg} / \mathrm{kg} /$ day), and an RSM high dose group ( $\mathrm{n}=5,200 \mathrm{mg} / \mathrm{kg} /$ day). Nude mice were anesthetized with sodium pentobarbital $(50 \mathrm{mg} / \mathrm{kg}$ i.p.) at the end of the study. To quantify tumor progression, in vivo imaging of liver tumors was performed by Xenogen IVIS 2,3 , and 4 weeks after tumor implantation. All animal protocols in the study were performed in accordance with international ethical guidelines and the National Institutes of Health Guide concerning the Care and Use of Laboratory Animals. All experiments and the use of animals in this study was approved by the Institutional Animal Care and Use Committee of Guagnzhou University of Traditional Chinese medicine, China.

\section{Statistical analysis}

All statistical analyzes were performed by Statistical Product and Service Solutions (SPSS) 20.0 software. One-way analysis of variance (ANOVA) followed by the Dunnett's post hoc test was used for multiple groups comparisons. Our data are expressed as mean \pm standard deviation (SD). A value of $P<0.05$ was considered significant.

\section{Results}

\section{HPLC analysis of RSM}

The constituents of the ethanol extracts of RSM were analyzed and identified by HPLC. As shown in Fig. 2, compounds represented by four main peaks of the HPLC chromatogram were identified as TIIA, TI, CT, and DH-TI.

\section{Chemical composition and targets of RSM}

In total, 202 compounds were collected from RSM. Sixtyfive candidate molecules were obtained with $\mathrm{OB} \geq 30 \%$ and $D L \geq 0.18$. Notably, the OB values of salvianolic acid 


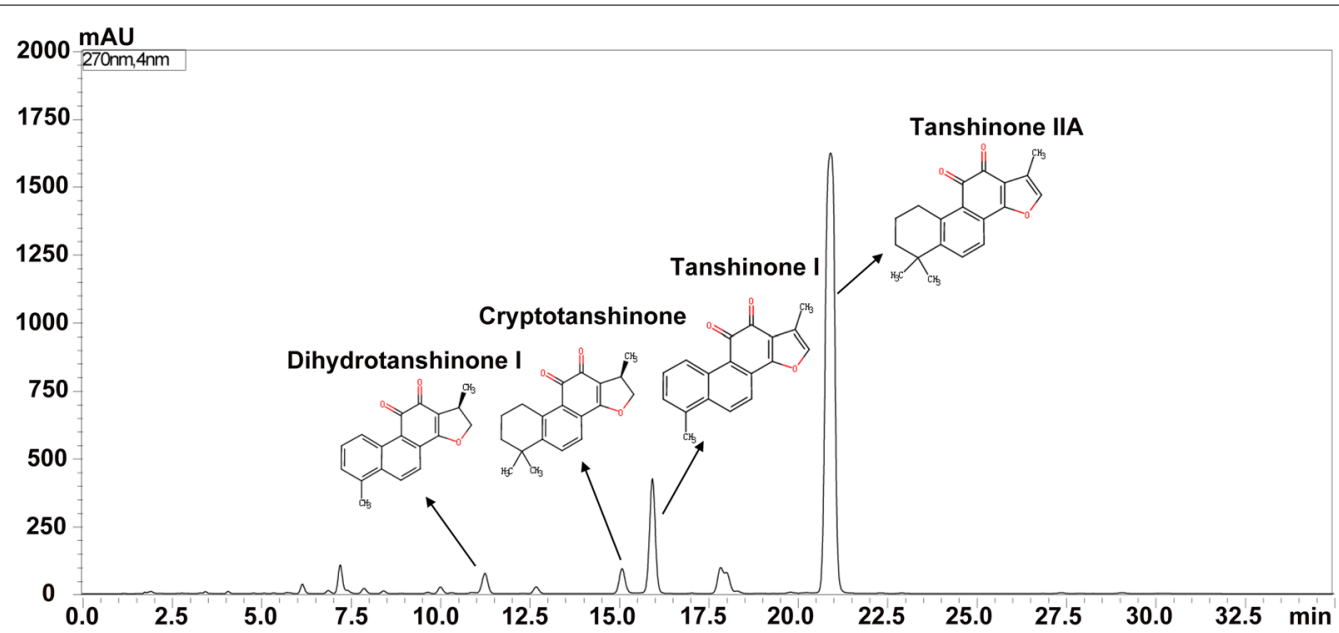

Fig. 2 RSM analyzed by HPLC. From right to left, the four major peaks represent: tanshinone IIA, tanshinone I, cryptotanshinone, and dihydrotanshinone I

B and salvianolic acid A were lower than $30 \%$; however, both are widely used to treat liver disease in vivo [32, $33]$ and in vitro [34, 35]. Therefore, these two molecules were also employed as candidate molecules, making a total of 67 active ingredients. Detailed information on active molecules in RSM is presented in Additional file 1: Table S1. Among the 67 compounds obtained, five candidate molecules had no targets. Finally, 62 chemical compounds yielded 101 putative targets. The details of these targets are shown in Additional file 2: Table S2.

\section{Compound-compound targets network analysis}

RSM exerts a wide range of biological and pharmacological effects through a variety of molecules and targets. To elucidate the complex interactions of RSM constituents and their corresponding targets at the system level, we constructed a network based on the potential compounds of RSM and candidate targets. The network consists of 163 nodes (62 compound nodes and 101 compound target nodes) and 1322 edges (Fig. 3). In Fig. 3, red $\mathrm{V}$ represents RSM, pink hexagons represent compounds of RSM, and blue circles represent compound targets. The average value (the number of connections that each node has to other nodes) of the candidate compounds was 21.3 , and the average value of the 19 compounds was greater than 30, indicating that RSM modulates multiple targets by multiple components to exert various therapeutic effects. These are potential active compounds of RSM due to their key positions in this network: tanshinone IIA (degree $=40)$ and cryptotanshinone (degree $=35$ ). Taking tanshinone IIA as an example, this molecule exhibits extensive pharmacological activities, with anti-coagulation, anti-apoptosis, and anti-oxidative properties, by mediating the activation of retinoid $\mathrm{X}$ receptor alpha 1 , inducible nitric oxide synthase, and BCL2, the apoptosis regulator [36]. Additionally, the results suggested that many targets were hit by multiple compounds in the network. ESR1, AR, and PTGS2 are targeted by 58,55 , and 50 compounds. These targets play critical roles in processes such as cell proliferation and inflammation [37, 38].

\section{Identification of candidate protein targets associated with HCC}

Overall, 5730 HCC-related targets were obtained from the GeneCards database, and 153 HCC-related targets were collected from the OMIM database. In total, 5617 HCC-related targets were identified following the deletion of duplicate targets. To elucidate the pharmacological mechanism of action of RSM in human HCC, a PPI network was determined and GO and pathway enrichment analysis was performed on the common targets of RSM and HCC. Seventy-two common targets were obtained. The details of targets are shown in Additional file 3: Table S3.

\section{PPI network}

We constructed a protein-protein interaction network, which denoted the relationship among 72 HCC-related targets to determine the importance of candidate targets. One target was no gene-gene interaction, and another target was not found in the above two databases. The network contained 70 nodes and 571 edges (Fig. 4). A hub node was defined as two-times greater than the average node degree in the network [39]. The average node degree (the number of targets associated with it) of the 


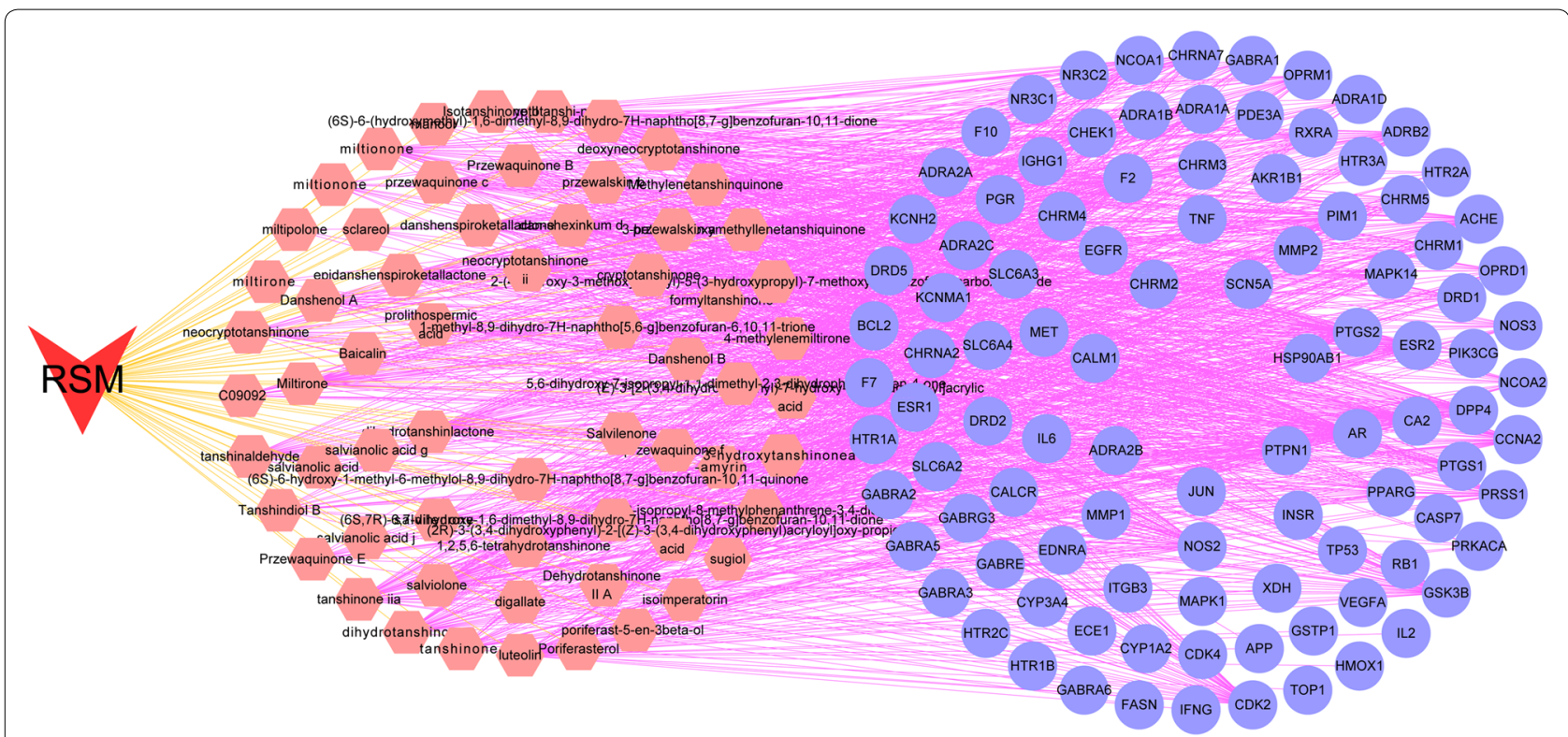

Fig. 3 Compound-compound target network. RSM consists of 62 compounds and 101 compound targets (red V represents RSM; pink hexagons represent compounds of RSM; blue circles represent compound targets)

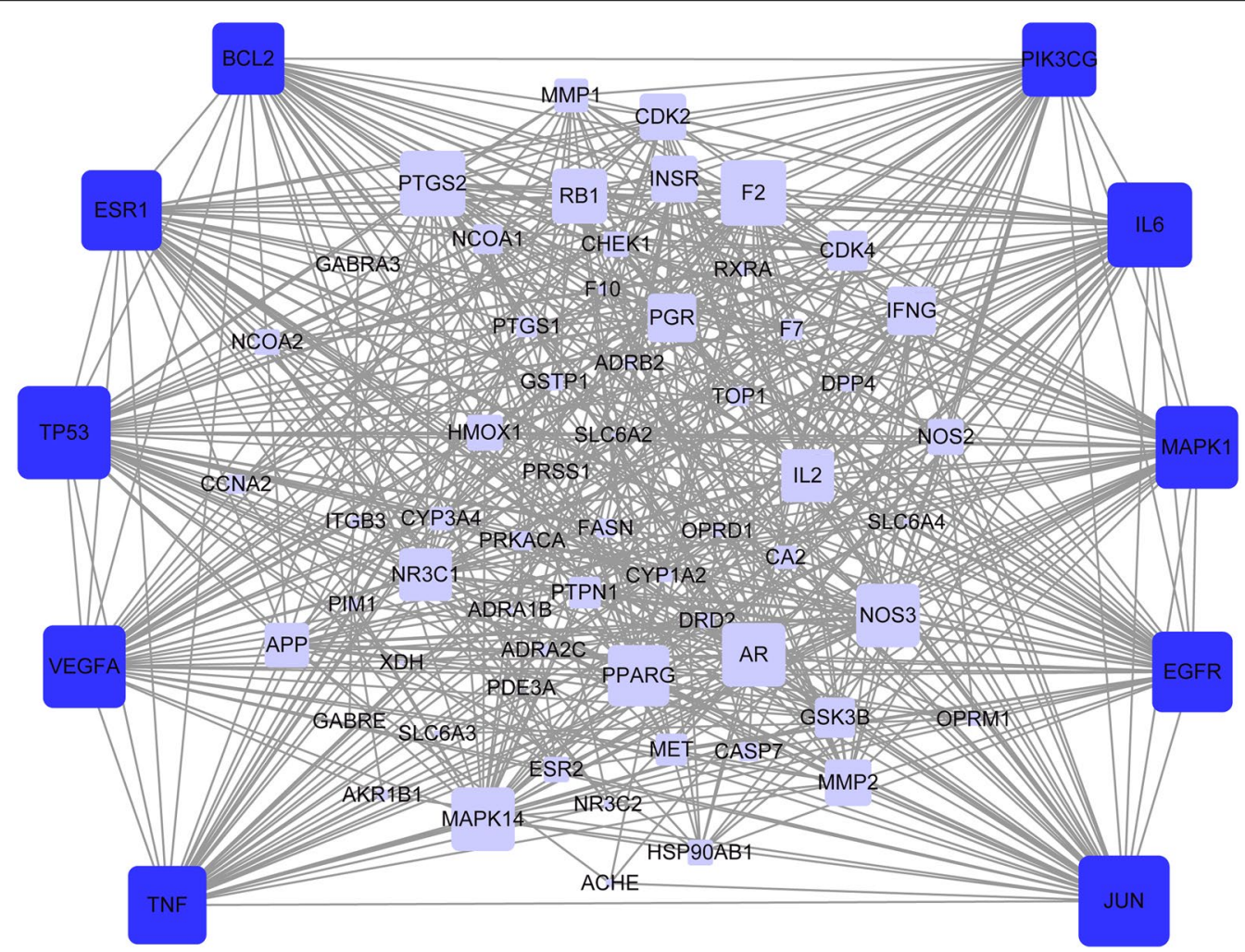

Fig. 4 Protein-protein interaction (PPI) network. The nodes get larger with increasing degree. Edges: PPIs between putative targets of RSM and their interactive partners; blue round rectangular nodes: common targets of RSM and HCC; dark blue round rectangular nodes: hub targets of RSM and HCC 
HCC-related targets was 32.6. Therefore, the hub nodes including TNF, PIK3CG, VEGFA, IL6, EGFR, MAPK1, JUN, TP53, BCL2, and ESR1 contained over 32.6 degrees. The number of edges per node as somewhat large (44 in TP53, 43 in JUN, 40 in IL6, 39 in MAPK1, 39 in VEGFA, 38 in ESR1, 38 in EGFR, 37 in TNF, 35 in PIK3CG, and 34 in BCL2). The network results suggest that the abovementioned genes may represent hub genes for the development of HCC. EGFR is expressed at high levels in cancer cells, and its activation EGFR appears to be important for tumor progression and growth [40]. Thus, RSM may act on HCC by targeting EGFR.

\section{Gene ontology and pathway enrichment analysis for targets}

To elucidate the biological characteristics of putative targets, functional enrichment analysis was performed for the target genes. The results, and detailed information on the GO targets, and pathways are shown in Additional file 4: Table S4. The 15 most significantly enriched terms in biological process (BP), molecular function (MF), and cellular component (CC) categories $(P<0.05)$ are listed in Fig. 5 . Figure 5 indicates that RSM may regulate cell proliferation, cell growth, and apoptotic processes, via protein binding, enzyme binding, and protease binding in the plasma membrane, nucleus, and cytoplasm to exert antiHCC potential. A pathway analysis was performed to explore the underlying mechanisms of RSM action for treatment of $\mathrm{HCC}$. The results demonstrated that 68 targets were mapped into the 99 KEGG pathways, including pathways in cancer, PI3K/AKT signaling, and proteoglycans in cancer, while four of 72 targets were not mapped into pathways. The 15 most significant pathways $(P<0.05)$ are shown in Fig. 6. Cancer signaling pathways displayed the highest number of target connections (degree $=22$ ), followed by PI3K/ AKT signaling pathways with 17 targets, and proteoglycans in cancer with 12 targets. The PI3K/AKT pathway is closely related to the proliferation, differentiation, apoptosis, migration, and adhesion of tumor cells involving multiple targets, including EGFR, BCL2, GSK3B, CDK2, and CDK4. Therefore, the data provided theoretical evidence that RSM may activate P13K/AKT signaling pathways in HCC.

\section{RSM inhibits the proliferation of human HCC cells}

To explore the effects of RSM on human HCC cells, MHCC97-H and HepG2 cells were incubated with increasing doses of RSM for $24 \mathrm{~h}$. Cell viability was

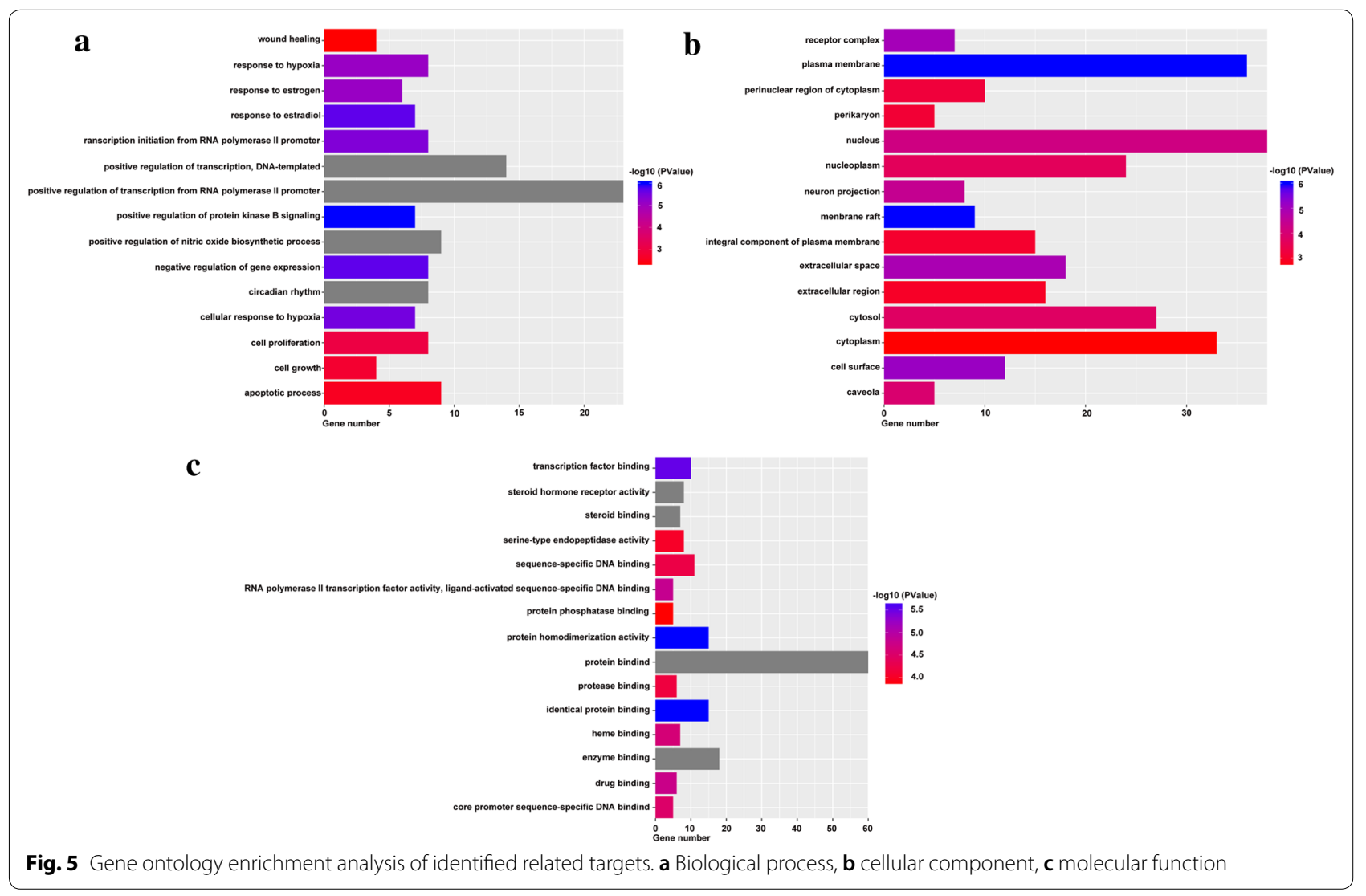




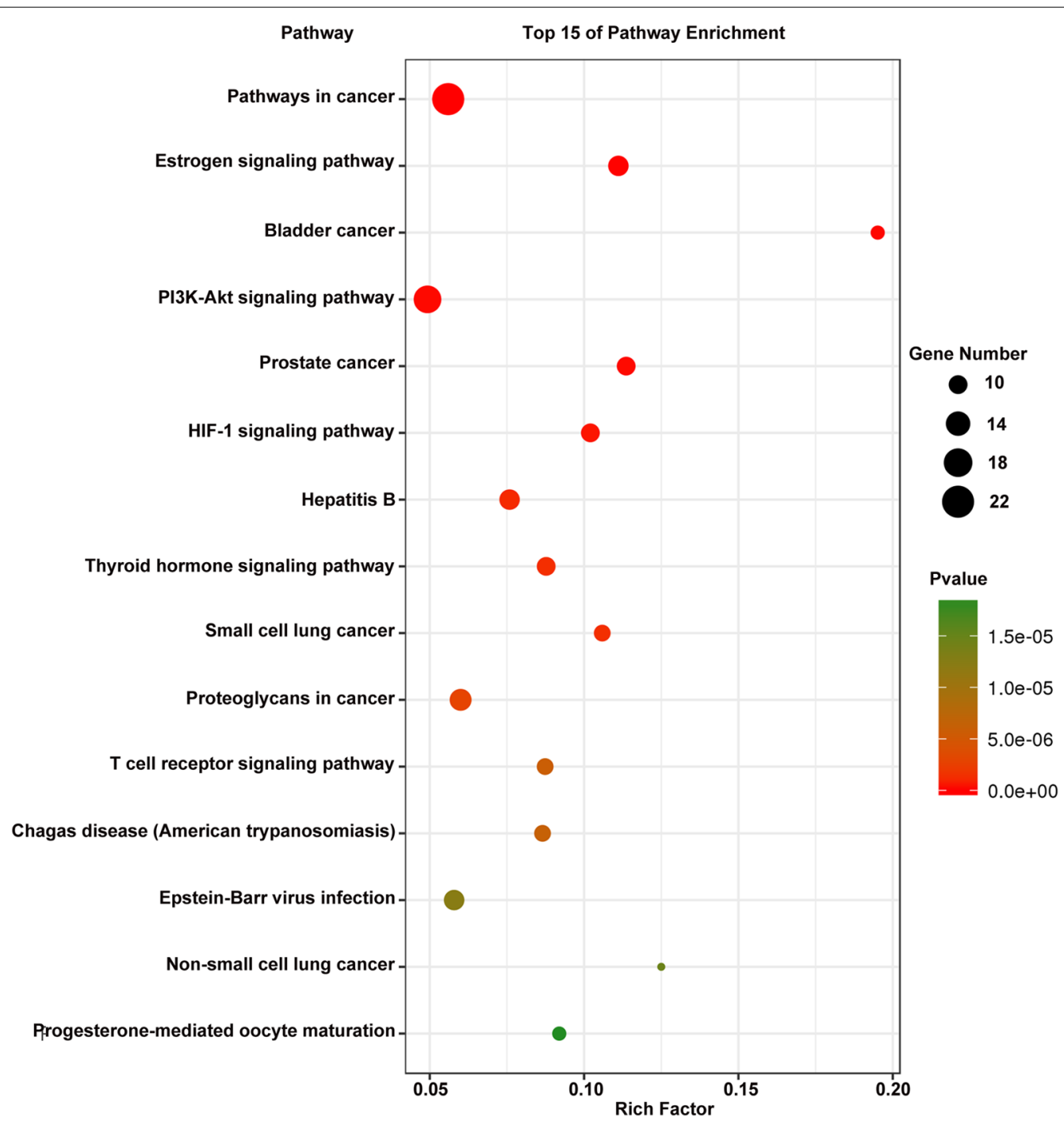

Fig. 6 Pathway analysis for identified related targets

assessed by MTT assay. The results of the MTT assay suggested that RSM significantly inhibited the viability of MHCC97-H and HepG2 cells (Fig. 7a, b). In a colony formation assay, RSM decreased colony formation at all indicated doses (Fig. 7c, d). These data suggested that RSM can inhibit HCC cell viability and proliferation.

\section{RSM induces cellular apoptosis and arrests cell cycle progression in the $\mathrm{G} 2 / \mathrm{M}$ phase}

We next investigated whether RSM affects cell cycle arrest and cellular apoptosis via flow cytometry. Administration of RSM at $5-20 \mu \mathrm{g} / \mathrm{mL}$ led to a significant increase in the number of apoptotic cells (Fig. 8a). As shown in Fig. 8b, we also assessed RSM-induced apoptosis by western blot. The results suggested that the expression of the apoptosis-related protein $\mathrm{Bcl}-2$ decreased and Bax increased after treatment with RSM. Furthermore, RSM induced cell cycle arrest in MHCC97$\mathrm{H}$ and HepG2 cells (Fig. 8c). These results suggest that RSM might induce apoptosis and cell cycle arrest.

\section{RSM inhibits human HCC cell migration and invasion}

To investigate the migratory ability of RSM in human HCC cells, wound healing and Transwell migration assays were performed. As shown in Fig. 9a, unlike in the control group, migration was markedly inhibited in cells treated with RSM. The Transwell migration assay also showed that RSM treatment inhibited the migration of cells in a dose-dependent manner (Fig. 9b). Moreover, the treatment of MHCC97-H and HepG2 cells with $5-20 \mu \mathrm{g} / \mathrm{mL}$ RSM for $24 \mathrm{~h}$ inhibited the number of 
a

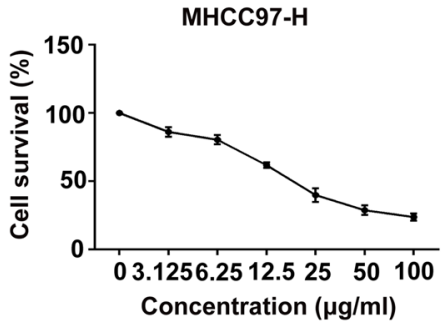

c

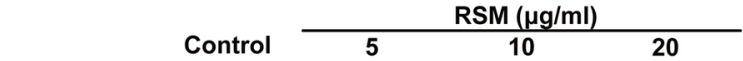

b

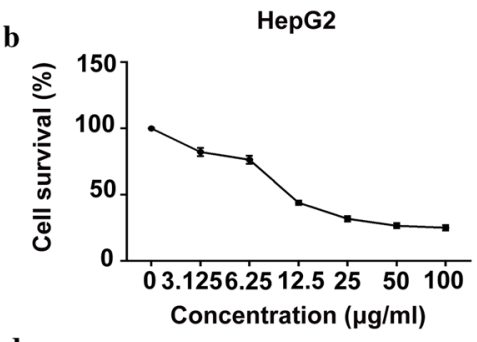

d

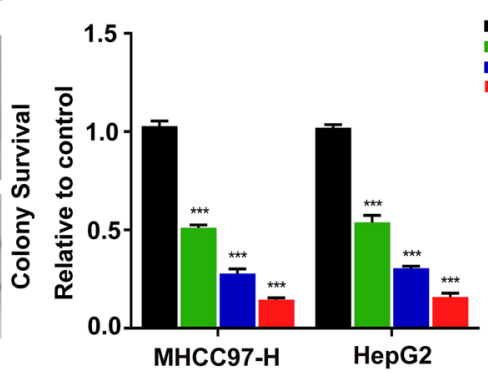

Fig. 7 RSM inhibits cell viability. a Viability of MHCC97-H and $\mathbf{b}$ HepG2 cells following $24 \mathrm{~h}$ incubation with the indicated doses of RSM. All data are presented as mean \pm standard deviation $(S D ; n=4)$. c Colony formation assay was performed using MHCC97-H and HepG2 cells treated with RSM. A representative of three experiments is shown. $\mathbf{d}$ Colony formation is presented as mean $\pm \mathrm{SD}(\mathrm{n}=3),{ }^{*} P<0.05,{ }^{* *} P<0.01$, ${ }^{* * *} P<0.001$ versus the control group

invading cells (Fig. 9b). These results confirmed that RSM inhibited the migration and invasion of cancer cells.

\section{RSM down-regulates EGFR expression, and attenuates $\mathrm{PI} 3 \mathrm{~K} / \mathrm{AKT}$ signaling in human HCC cells}

The network pharmacology results described above, suggested that the EGFR and PI3K/AKT signaling pathways might account for the mechanism of RSM action in on HCC. Therefore, we evaluated the expression levels of EGFR, PI3K, AKT, and p-AKT by western blot. As shown in Fig. 10, the expression of EGFR decreased in both MHCC97-H and HepG2 cells treated with 5-20 $\mu \mathrm{g} /$ $\mathrm{mL}$ RSM for $24 \mathrm{~h}$. Next, we assessed the protein levels of PI3K, AKT, and p-AKT. The results indicated that RSM significantly decreased the expression of p-AKT and PI3K, whilst total AKT expression was not changed. Taken together, these results suggest that the effect of RSM in HCC might be related to the EGFR and PI3K/ AKT signal transduction pathways in human HCC cells.

\section{RSM inhibits the growth of liver tumors in nude mice following orthotopic liver transplantation}

We explored the anti-HCC potential of RSM in vivo. Implantation of MHCC-97L-luciferase facilitated monitoring of liver cancer progression by bioluminescence imaging to quantify bioluminescence emitted from cancer cells. Three weeks after implantation, there was a significant inhibition in luminescence in the livers of mice in the RSM $(100 \mathrm{mg} / \mathrm{kg}, 200 \mathrm{mg} / \mathrm{kg})$ group compared to that in the control group, as visualized using Xenogen imaging (Fig. 11a). The nude mice were sacrificed after 4 weeks and the size of orthotopic liver transplantations were measured in each group. The tumor volume of the orthotopic liver transplantation decreased significantly after RSM treatment $(P<0.05)$ (Fig. 11b).

\section{Discussion}

In this study, RSM inhibited cellular proliferation, invasion, and migration, and induced cell cycle arrest at the G2/M phase and cellular apoptosis associated with HCC in vitro through modulation of the PI3K/AKT pathway and EGFR. RSM is one of the most popular Chinese medicinal herbs. Studies have demonstrated that RSM or RSM extracts may have positive effects in patients with liver fibrosis [41, 42], dementia [43-45], osteoporosis [46], chronic renal failure [47-49], and fulminant hepatic failure [50]. Previous research has shown that RSM extracts inhibit proliferation and induce apoptosis in HepG2 cells [51]. However, the underlying mechanisms of the pharmacological action of RSM in HCC therapy remain unclear.

We analyzed the putative active compounds and targets of RSM through a network pharmacology approach, a powerful tool that has emerged to better understand the underlying mechanisms of action of TCM. To elucidate the pharmacological mechanism of RSM acting 


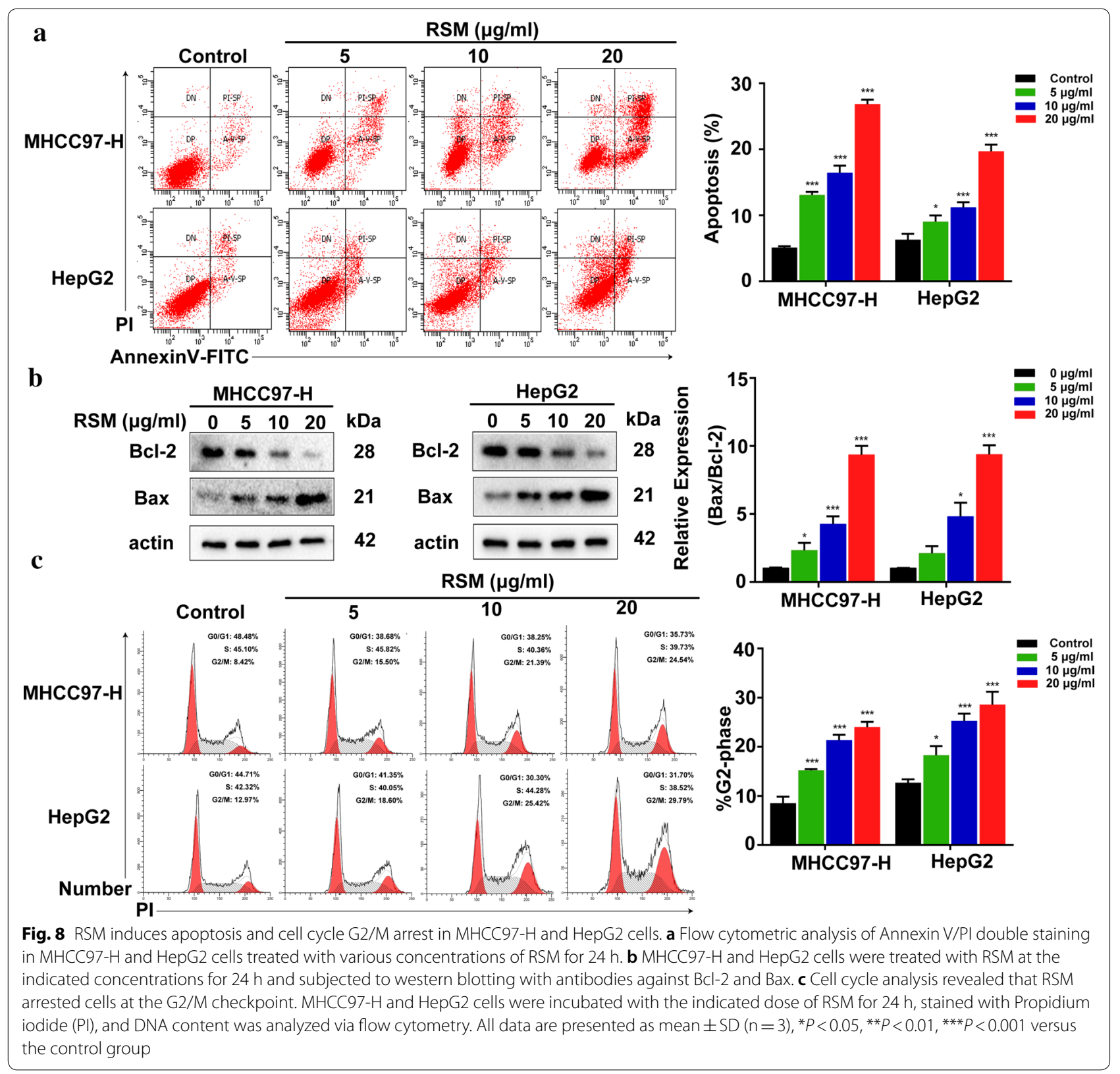

on human HCC, we performed a PPI network analysis. The PPI network analysis revealed that TNF, PIK3CG, VEGFA, IL6, EGFR, MAPK1, JUN, TP53, BCL2, and ESR1 may represent hub genes against HCC. EGFR is a transmembrane receptor tyrosine kinase and a receptor for members of the ErbB family of extracellular protein ligands [52]. EGFR signaling modulates diverse cell functions and promotes cellular proliferation, differentiation, migration, growth, and survival [53]. Mutations in EFGR lead to its overexpression (upregulation or amplification), which is associated with many cancers, including lung cell carcinoma [54], glioblastoma [55], anal cancer [56], and epithelial tumors in the head and neck [57]. Previous studies have indicated that EGFR activation plays a pivotal role in the development of HCC $[58,59]$; however, there is no evidence to support the downregulation of EGFR expression by RSM. In this study, we evaluated EGFR expression in MHCC97-H and HepG2 cells. The results showed that RSM could decrease EGFR expression in a dose-dependent manner compared to that in the control group. Furthermore, EGFR is also an upstream protein in the PI3K/AKT signal transduction pathway, which is an important target in cancer research [60, 61].

The pathway analysis results obtained by DAVID suggested that pathways in cancer, PI3K/AKT signaling pathway, and proteoglycans in cancer may be closely 


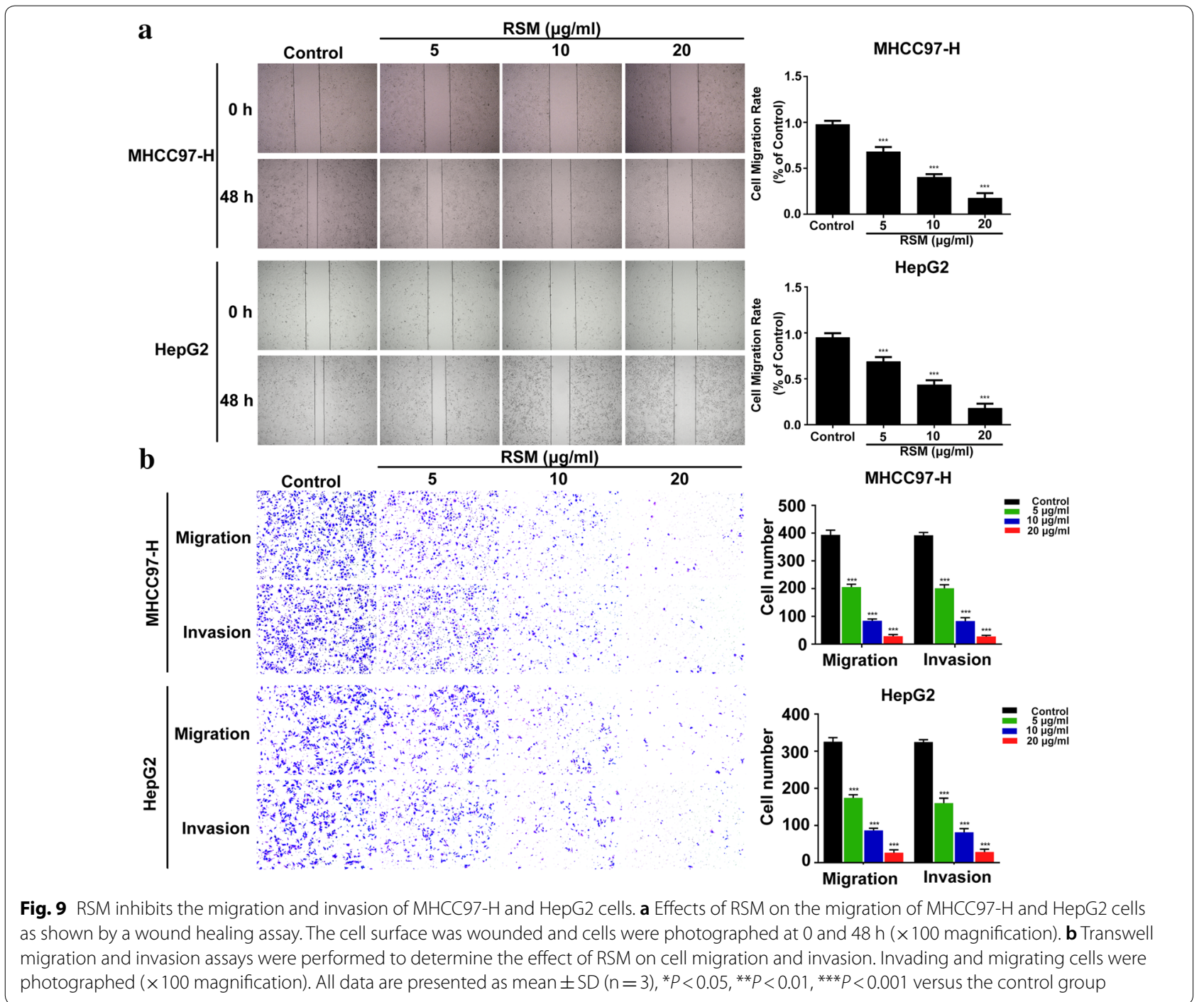

related to HCC progression. Phosphatidylinositol-3-kinases (PI3Ks) are a family of enzymes that phosphorylate the 3-position hydroxyl group of the inositol ring of phosphatidylinositol. PI3K contains two domains: a catalytic domain, P110, and a regulatory domain, P85 [62]. AKT, also referred to as protein kinase B, is a serine/threonine-specific protein kinase that plays a critical role in multiple cellular processes. The PI3K/AKT signaling pathway plays a key role in normal cellular processes involved in growth, glucose metabolism, proliferation, survival, apoptosis, motility, ribosomal function, gene transcription, migration, and invasion, via phosphorylation of a variety of substrates by the serine/threonine kinase AKT [63, 64]. A growing body of evidence suggests that aberrant activation of the PI3K/AKT pathway promotes the development and progression of multiple human malignancies $[65,66]$, such as lung cancer [67], ovarian cancer [68], and oral squamous cell carcinoma [69]. Cryptotanshinone, a natural active compound of $S$. miltiorrhiza Bunge, has been shown to affect cell cycle arrest and apoptosis through the PI3K/Akt/NFKB and JAK2/STAT3 pathways in cholangiocarcinoma cells [70]. Tanshinone IIA, one of the main compounds of $S$. miltiorrhiza Bunge, has been shown to inhibit the growth of cancer cells via autophagy and apoptosis, which is related to the Beclin-1/Atg7/Atg12-Atg5 and PI3K/Akt/ mTOR pathways [71]. In the present study, high expression of phosphorylate AKT (p-AKT) and PI3K in the 


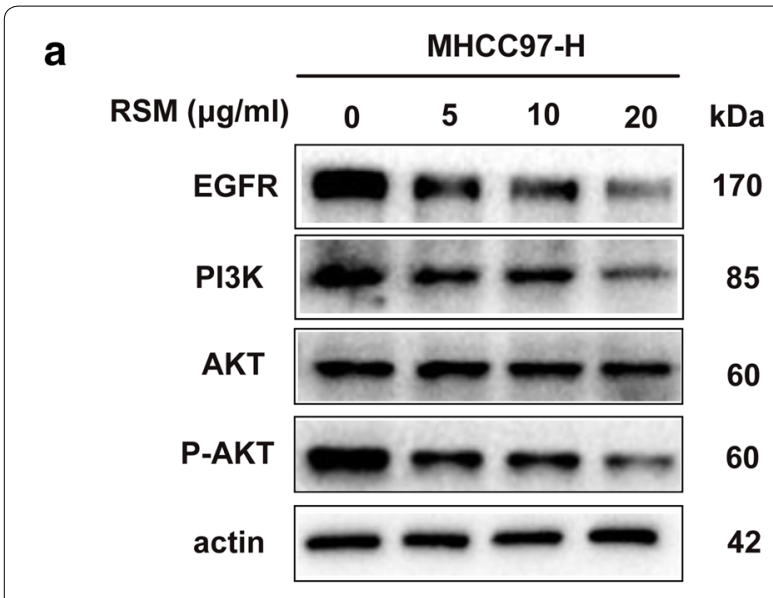

b

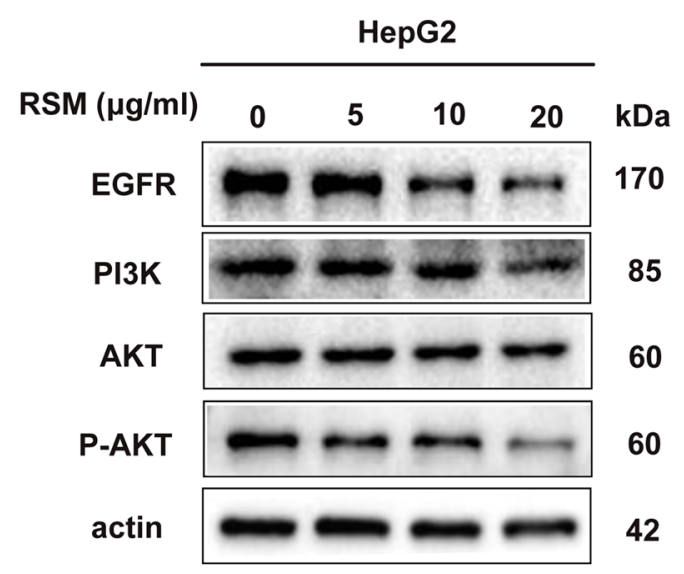

Fig. 10 RSM down-regulates EGFR expression, and attenuates PI3K/AKT signaling in human HCC cells. Western blot analysis of EGFR, PI3K, AKT, and $\mathrm{p}-\mathrm{AKT}$ in a MHCC97-H and $\mathbf{b} \mathrm{HepG} 2$ cells. Data are presented as mean $\pm \mathrm{SD}(\mathrm{n}=3),{ }^{*} P<0.05,{ }^{* *} P<0.01,{ }^{* * *} P<0.001$ versus the control group

control group indicated the activation of the PI3K/AKT signal transduction pathway. Compared to levels in the control group, the levels of p-AKT and PI3K in the treatment group were significantly decreased, and the expression of total AKT remained constant. Therefore, our results revealed that RSM plays a significant anti-HCC role, which is mediated by the PI3K/AKT pathway.

This study demonstrates, for the first time, that RSM can efficiently suppress cellular proliferation and induce G2/M checkpoint arrest and apoptosis. In addition, RSM also affects the migration and invasion ability of MHCC97-H and HepG2 cells. Taken together, our results indicate that RSM acts on HCC through the EGFR and PI3K/AKT signaling pathways. Due to budgetary and time constraints, only a few key molecules and mechanisms involved in the antitumor activity of RSM on HCC were studied here. Therefore,
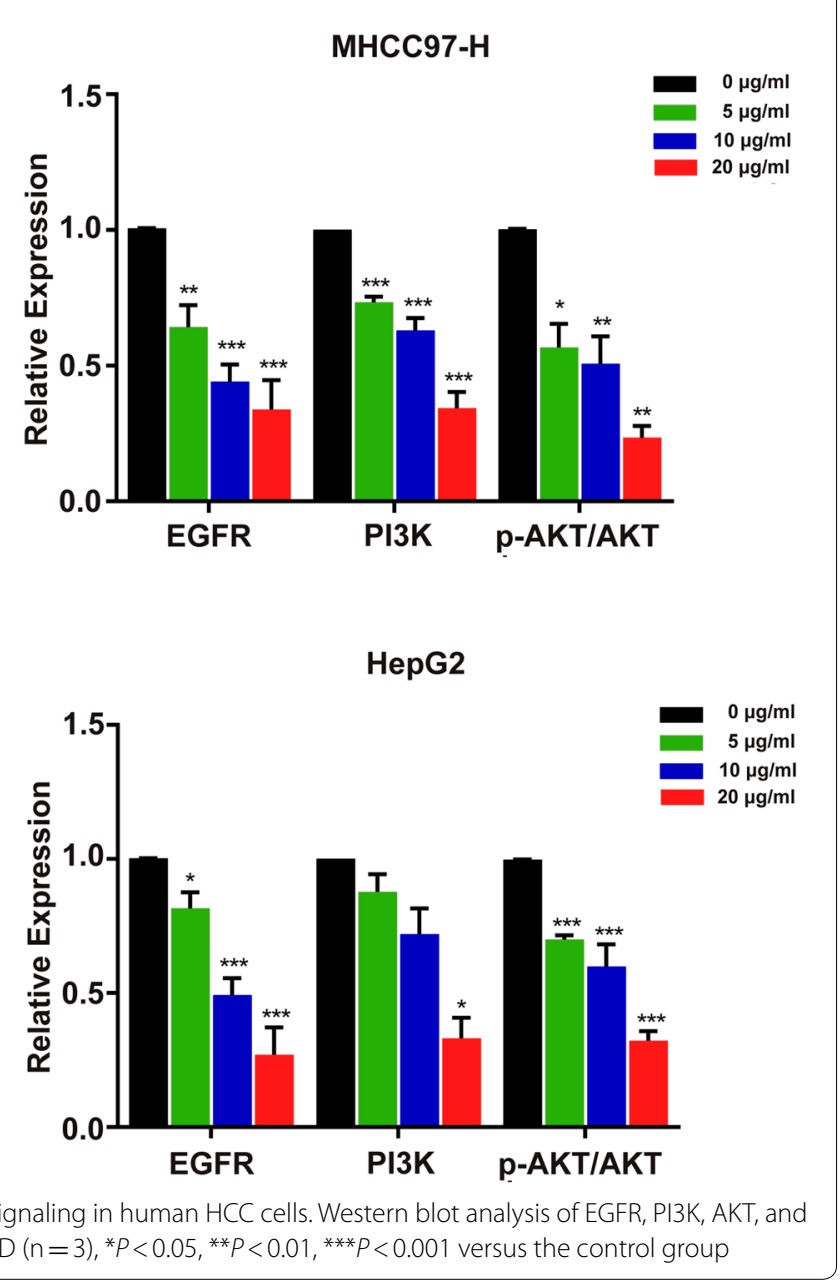

other potential mechanisms that may underly the antitumor action of RSM in vitro and in vivo await further elucidation. Despite its limitations, this study provides powerful and preliminary data to support the future evaluation of RSM in HCC. RSM may be a potential anti-HCC inhibitor, which can be developed as a therapeutic option for the treatment of cancer.

\section{Conclusions}

Taken together, our studies illustrate that RSM could suppress proliferation, induce G2/M checkpoint arrest and apoptosis, and impair the migration and invasion ability of MHCC97-H and HepG2 cells in vitro, which may be linked to the EGFR and PI3K/AKT signaling pathways. In addition, RSM could inhibit liver tumor growth of orthotopically implanted HCC in nude mice. 

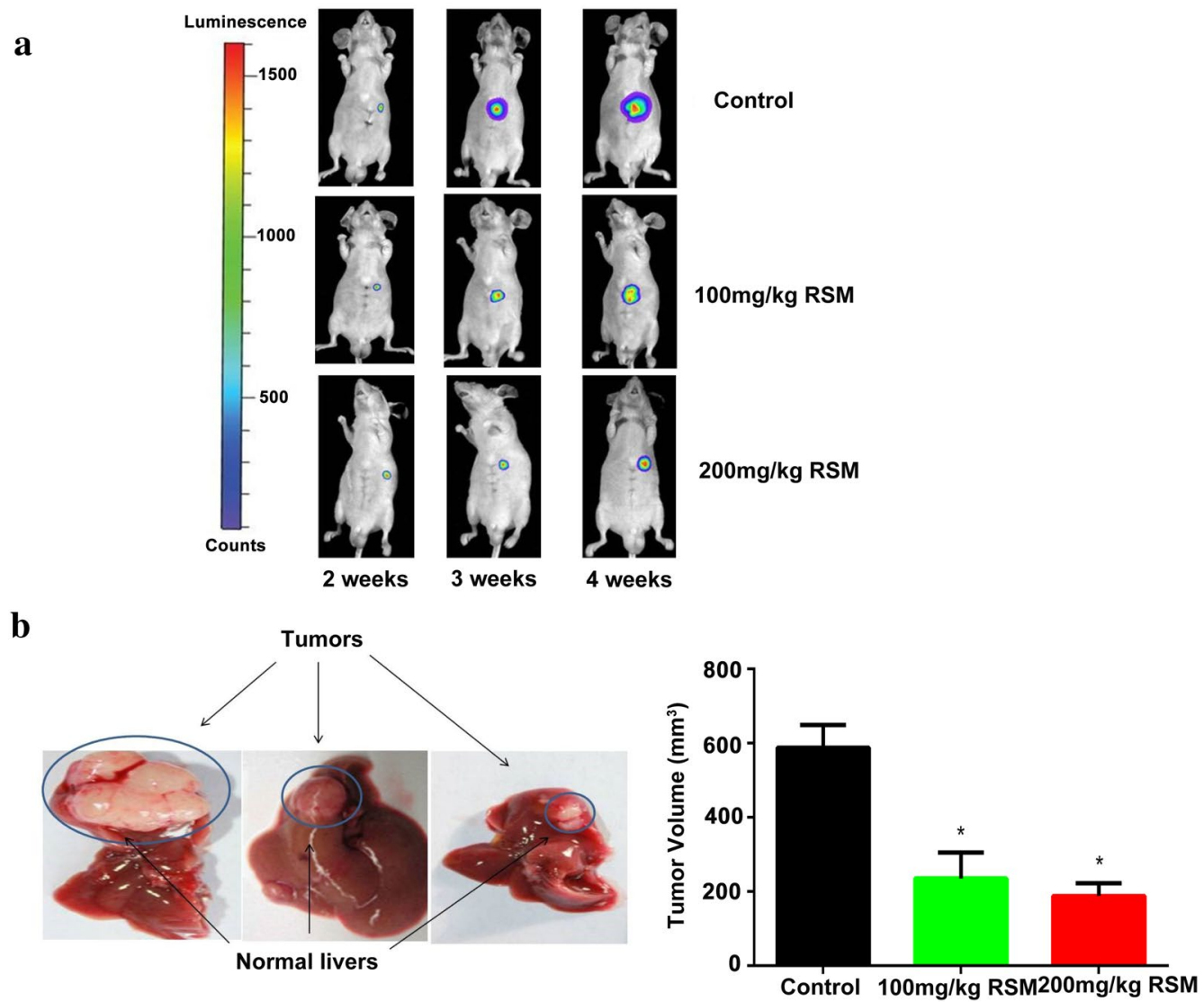

Fig. 11 RSM suppresses the growth of liver tumors in nude mice orthotopically implanted with HCC. a In vivo detection of liver luciferase signals revealed a significant inhibition of luminescence in RSM-treated mice compared with control mice 3 weeks after implantation. $\mathbf{b}$ There was a significant change in the volume of orthotopic transplanted liver tumors following RSM treatment $(P<0.05)$. Data are presented as mean \pm SD $(n=5)$, ${ }^{P}<0.05$ versus the control group

\section{Additional files}

Additional file 1: Table S1. List of active ingredients in Radix Salviae Miltiorrhizae (RSM)

Additional file 2: Table S2. List of the chemical compounds and putative targets of RSM following screening.

Additional file 3: Table S3. List of hepatocellular carcinoma (HCC)-related targets identified from the GeneCards and OMIM databases and common targets of RSM and HCC.

Additional file 4: Table S4. Gene ontology (GO) terms and pathways.

\section{Abbreviations}

RSM: Radix Salviae Miltiorrhizae; HCC: human hepatocellular carcinoma; EGFR: epidermal growth factor receptor; PI3K: phosphatidylinositol 3-kinase; AKT protein kinase $\mathrm{B} ; \mathrm{BCl}-2$ : B-cell lymphoma-2; TIIA: tanshinone IIA; CT: cryptotanshinone; DH-TI: dihydrotanshinone I; TI: tanshinone I; VEGFR: vascular endothelial growth factor receptor: HER2: human epidermal growth factor receptor-2; MEK: mitogen-activated protein kinase kinase; ERK: extracellular signal-regulated kinase; PARP: poly ADP-ribose polymerase; mTOR: mammalian target of rapamycin; TCM: traditional chinese medicine; TCMSP: Traditional Chinese Medicine Systems Pharmacology; ADME: absorption, distribution, metabolism, and excretion; DL: drug-likeness; OB: oral bioavailability; OMIM: Online Mendelian Inheritance in Man; DMEM: Dulbecco's modified Eagle's medium; FBS: fetal bovine serum; HPLC: high-performance liquid chromatography; PBS: phosphate-buffered saline; PI: propidium iodide; FITC: fluorescein; SDS-PAGE: sodium dodecyl sulfate polyacrylamide gel electrophoresis; PVDF: polyvinylidene difluoride; BP: biological process; MF: molecular function; CC: cellular component; DAVID: The Database for Annotation, Visualization and Integrated Discovery.

\section{Acknowledgements}

The authors thank members of the Institute of Clinical Pharmacology at the Guangzhou University of Chinese Medicine for their assistance. The authors thank Dr. Hong for her critical evaluation and advice during the preparation of the manuscript.

\section{Authors' contributions}

$Y L$ conducted the in vitro experiments and drafted the manuscript; YF conducted the animal experiments; $\mathrm{MH}$ and QW designed the study and revised the final manuscript; SSB, YJH, LS and GQH contributed to data analysis; SL, $S Y L, M M$, and HLS provided advice during the study and manuscript preparation. All authors read and approved the final manuscript.

\section{Funding}

This study was supported by grants from Guangzhou Science Technology and Innovation Commission Technology Research Projects (No. 201805010005) to QW. Funders provided financial support for the study. 


\section{Availability of data and materials}

The datasets used and/or analyzed during the current study are available from the corresponding author on reasonable request.

\section{Ethics approval and consent to participate}

All animal protocols in the study were performed in accordance with international ethical guidelines and the National Institutes of Health Guide concerning the Care and Use of Laboratory Animals. All experiments involving animals were approved by the Institutional Animal Care and Use Committee of Guangzhou University of Traditional Chinese Medicine.

\section{Consent for publication}

Not applicable.

\section{Competing interests}

The authors declare that they have no competing interests.

\section{Author details}

${ }^{1}$ Institute of Clinical Pharmacology, Guangzhou University of Chinese Medicine, Guangzhou 510405, China. ${ }^{2}$ Department of Traumatology, General Hospital of Ningxia Medical University, Yinchuan 750004, China. ${ }^{3}$ Department of Orthopaedics and Traumatology, Li Ka Shing Faculty of Medicine, The University of Hong Kong, Hong Kong, China. ${ }^{4}$ Department of Gastroenterology, Second Affiliated Hospital of Guangzhou Medical University, Guangzhou 501260, China. ${ }^{5}$ School of Chinese Medicine, Li Ka Shing Faculty of Medicine, The University of Hong Kong, Hong Kong, China. ${ }^{6}$ Department of Pharmacology \& Toxicology, University of Kansas, Lawrence, KS, USA.

Received: 2 May 2019 Accepted: 26 July 2019

Published online: 06 August 2019

\section{References}

1. Balogh J, Victor D 3rd, Asham EH, Burroughs SG, Boktour M, Saharia A, Li X, Ghobrial RM, Monsour HP Jr. Hepatocellular carcinoma: a review. J Hepatocell Carcinoma. 2016;3:41-53. https://doi.org/10.2147/JHC.S6114 6.

2. Forner A, Reig M, Bruix J. Hepatocellular carcinoma. Lancet. 2018;391(10127):1301-14. https://doi.org/10.1016/S0140-6736(18)30010 -2 .

3. Singh S, Singh PP, Roberts LR, Sanchez W. Chemopreventive strategies in hepatocellular carcinoma. Nat Rev Gastroenterol Hepatol. 2014;11(1):4554. https://doi.org/10.1038/nrgastro.2013.143.

4. Amicone L, Marchetti A. Microenvironment and tumor cells: two targets for new molecular therapies of hepatocellular carcinoma. Transl Gastroenterol Hepatol. 2018;3:24. https://doi.org/10.21037/tgh.2018.04.05.

5. White DL, Thrift AP, Kanwal F, Davila J, Serag HB. Incidence of hepatocellular carcinoma in All 50 United States, from 2000 through 2012. Gastroenterology. 2017;152(4):812-20. https://doi.org/10.1053/j.gastr 0.2016 .11 .020

6. Daher S, Massarwa M, Benson AA, Khoury T. Current and future treatment of hepatocellular carcinoma: an updated comprehensive review. J Clin Transl Hepatol. 2018;6(1):69-78. https://doi.org/10.14218/ JCTH.2017.00031.

7. Gao LN, Cui YL, Wang QS, Wang SX. Amelioration of Danhong injection on the lipopolysaccharide-stimulated systemic acute inflammatory reaction via multi-target strategy. J Ethnopharmacol. 2013;149(3):772-82. https://doi.org/10.1016/j.jep.2013.07.039.

8. Cheng TO. Cardiovascular effects of Danshen. Int J Cardiol. 2007;121(1):922. https://doi.org/10.1016/j.ijcard.2007.01.004

9. Cheng TO. Danshen: a versatile Chinese herbal drug for the treatment of coronary heart disease. Int J Cardiol. 2006;113(3):437-8. https://doi. org/10.1016/j.ijcard.2005.10.026.

10. Kang DG, Yun YG, Ryoo JH, Lee HS. Anti-hypertensive effect of water extract of Danshen on renovascular hypertension through inhibition of the renin angiotensin system. Am J Chinese Med. 2002;30(1):87-93. https ://doi.org/10.1142/S0192415×02000107.

11. Gu M, Zhang G, Su Z, Ouyang F. Identification of major active constituents in the fingerprint of Salvia miltiorrhiza Bunge developed by high-speed counter-current chromatography. J Chromatogr A. 2004;1041(1-2):239-43. https://doi.org/10.1016/j.chroma.2004.04.030.

12. Li YG, Song L, Liu M, Hu ZB, Wang ZT. Advancement in analysis of Salviae miltiorrhizae Radix et Rhizoma (Danshen). J Chromatogr A. 2009;1216(11):1941-53. https://doi.org/10.1016/j.chroma.2008.12.032.

13. Zhou LM, Zuo Z, Chow MSS. Danshen: an overview of its chemistry, pharmacology, pharmacokinetics, and clinical use. J Clin Pharmacol. 2005;45(12):1345-59. https://doi.org/10.1177/0091270005282630.

14. Bae WJ, Choi JB, Kim KS, Syn Ha U, Hong SH, Lee JY, Hwang TK, Hwang SY, Wang ZP, Kim SW. Inhibition of proliferation of prostate cancer cell line DU-145 in vitro and in vivo using Salvia miltiorrhiza Bunge. Chin J Integr Med. 2017;1:1. https://doi.org/10.1007/s11655-017-2801-5.

15. Kim JM, Noh EM, Song HK, Lee M, Lee SH, Park SH, Ahn CK, Lee GS, Byun EB, Jang BS, et al. Salvia miltiorrhiza extract inhibits TPA-induced MMP-9 expression and invasion through the MAPK/AP-1 signaling pathway in human breast cancer MCF-7 cells. Oncol Lett. 2017;14(3):3594-600. https ://doi.org/10.3892/ol.2017.6638.

16. Su CC. Tanshinone IIA inhibits gastric carcinoma AGS cells by decreasing the protein expression of VEGFR and blocking Ras/Raf/MEK/ERK pathway. Int J Mol Med. 2018;41(4):2389-96. https://doi.org/10.3892/ ijmm.2018.3407.

17. Jing Z, Fei WQ, Zhou JC, Zhang LM, Chen LX, Zhang XM, Liang X, Xie JS, Fang $Y$, Sui XB, et al. Salvianolic acid B, a novel autophagy inducer, exerts antitumor activity as a single agent in colorectal cancer cells. Oncotarget. 2016;7(38):61509-19. https://doi.org/10.18632/oncotarget.11385.

18. Li S, Zhang B. Traditional Chinese medicine network pharmacology: theory, methodology and application. Chin J Nat Med. 2013;11(2):110-20. https://doi.org/10.1016/S1875-5364(13)60037-0.

19. da Hao C, Xiao PG. Network pharmacology: a Rosetta Stone for traditional Chinese medicine. Drug Dev Res. 2014;75(5):299-312. https://doi. org/10.1002/ddr.21214.

20. Liu L, Du B, Zhang H, Guo X, Zhou Z, Xiu A, Liu C, Su S, Ai H. A network pharmacology approach to explore the mechanisms of Erxian decoction in polycystic ovary syndrome. Chin Med. 2018;13:46. https://doi. org/10.1186/s13020-018-0201-1.

21. Fang J, Wang L, Wu T, Yang C, Gao L, Cai H, Liu J, Fang S, Chen Y, Tan W, et al. Network pharmacology-based study on the mechanism of action for herbal medicines in Alzheimer treatment. J Ethnopharmacol. 2017;196:281-92. https://doi.org/10.1016/j.jep.2016.11.034

22. Zhang Y, Mao X, Su J, Geng Y, Guo R, Tang S, Li J, Xiao X, Xu H, Yang $H$. A network pharmacology-based strategy deciphers the underlying molecular mechanisms of Qixuehe Capsule in the treatment of menstrual disorders. Chin Med. 2017;12:23. https://doi.org/10.1186/s1302 0-017-0145-X

23. Wu L, Wang Y, Li Z, Zhang B, Cheng Y, Fan X. Identifying roles of "JunChen-Zuo-Shi" component herbs of QiShenYiQi formula in treating acute myocardial ischemia by network pharmacology. Chin Med. 2014;9:24. https://doi.org/10.1186/1749-8546-9-24.

24. Ru J, Li P, Wang J, Zhou W, Li B, Huang C, Li P, Guo Z, Tao W, Yang Y, et al. TCMSP: a database of systems pharmacology for drug discovery from herbal medicines. J Cheminform. 2014;6:13. https://doi. org/10.1186/1758-2946-6-13.

25. Xu X, Zhang W, Huang C, Li Y, Yu H, Wang Y, Duan J, Ling Y. A novel chemometric method for the prediction of human oral bioavailability. Int J Mol Sci. 2012;13(6):6964-82. https://doi.org/10.3390/ijms13066964.

26. Yu H, Chen J, Xu X, Li Y, Zhao H, Fang Y, Li X, Zhou W, Wang W, Wang Y. A systematic prediction of multiple drug-target interactions from chemical, genomic, and pharmacological data. PLoS ONE. 2012;7(5):e37608. https:// doi.org/10.1371/journal.pone.0037608.

27. Safran M. Human gene-centric databases at the weizmann institute of science: geneCards, UDB, CroW 21 and HORDE. Nucleic Acids Res. 2003;31(1):142-6. https://doi.org/10.1093/nar/gkg050.

28. Hamosh A, Scott AF, Amberger JS, Bocchini CA, McKusick VA. Online Mendelian Inheritance in Man (OMIM), a knowledgebase of human genes and genetic disorders. Nucleic Acids Res. 2005;33(Database issue):D514-7. https://doi.org/10.1093/nar/gki033.

29. Szklarczyk D, Franceschini A, Wyder S, Forslund K, Heller D, Huerta-Cepas J, Simonovic M, Roth A, Santos A, Tsafou KP, et al. STRING v10: protein-protein interaction networks, integrated over the tree of life. Nucleic Acids Res. 2015;43(Database issue):D447-52. https://doi.org/10.1093/nar/gku10 03. 
30. da Huang W, Sherman BT, Lempicki RA. Systematic and integrative analysis of large gene lists using DAVID bioinformatics resources. Nat Protoc. 2009;4(1):44-57. https://doi.org/10.1038/nprot.2008.211.

31. da Huang W, Sherman BT, Lempicki RA. Bioinformatics enrichment tools: paths toward the comprehensive functional analysis of large gene lists. Nucleic Acids Res. 2009;37(1):1-13. https://doi.org/10.1093/nar/gkn923.

32. Shi $X$, Zhao Y, Ding C, Wang Z, Ji A, Li Z, Feng D, Li Y, Gao D, Zhou J, et al. Salvianolic acid A alleviates chronic ethanol-induced liver injury via promotion of $\beta$-catenin nuclear accumulation by restoring SIRT1 in rats. Toxicol Appl Pharmacol. 2018;350:21-31. https://doi.org/10.1016/j. taap.2018.04.036.

33. Yan X, Jiang Z, Bi L, Yang Y, Chen W. Salvianolic acid A attenuates TNFalpha- and D-GalN-induced ER stress-mediated and mitochondrialdependent apoptosis by modulating $\mathrm{Bax} / \mathrm{BCl}-2$ ratio and calcium release in hepatocyte LO2 cells. Naunyn Schmiedebergs Arch Pharmacol. 2015;388(8):817-30. https://doi.org/10.1007/s00210-015-1116-3.

34. Li M, Lu Y, Hu Y, Zhai X, Xu W, Jing H, Tian X, Lin Y, Gao D, Yao J. Salvianolic acid $B$ protects against acute ethanol-induced liver injury through SIRT1mediated deacetylation of p53 in rats. Toxicol Lett. 2014;228(2):67-74. https://doi.org/10.1016/.jtoxlet.2014.04.011.

35. Zhang N, Hu Y, Ding C, Zeng W, Shan W, Fan H, Zhao Y, Shi X, Gao L, Xu $T$, et al. Salvianolic acid B protects against chronic alcoholic liver injury via SIRT1-mediated inhibition of CRP and ChREBP in rats. Toxicol Lett. 2017;267:1-10. https://doi.org/10.1016/j.toxlet.2016.12.010.

36. Shi MJ, Dong BS, Yang WN, Su SB, Zhang H. Preventive and therapeutic role of Tanshinone IIA in hepatology. Biomed Pharmacother. 2019;112:1. https://doi.org/10.8676/j.biopha.2019.108676.

37. Liu H, Liu K, Bodenner DL. Estrogen receptor inhibits interleukin-6 gene expression by disruption of nuclear factor kappaB transactivation. Cytokine. 2005;31(4):251-7. https://doi.org/10.1016/j.cyto.2004.12.008.

38. Fujimoto $\mathrm{N}$, Yeh S, Kang HY, Inui S, Chang HC, Mizokami A, Chang C. Cloning and characterization of androgen receptor coactivator, ARA55, in human prostate. J Biol Chem. 1999;274(12):8316-21. https://doi. org/10.1074/jbc.274.12.8316.

39. Li S, Zhang ZQ, Wu LJ, Zhang XG, Li YD, Wang YY. Understanding ZHENG in traditional Chinese medicine in the context of neuro-endocrineimmune network. IET Syst Biol. 2007;1(1):51-60. https://doi.org/10.1049/ iet-syb:20060032.

40. Seshacharyulu P, Ponnusamy MP, Haridas D, Jain M, Ganti AK, Batra SK. Targeting the EGFR signaling pathway in cancer therapy. Exp Opin Ther Targets. 2012;16(1):15-31. https://doi.org/10.1517/14728222.2011.64861 7.

41. Wang R, Wang J, Song F, Li S, Yuan Y. Tanshinol ameliorates CCI4-induced liver fibrosis in rats through the regulation of Nrf2/HO-1 and NF-kappaB/ IkappaBalpha signaling pathway. Drug Des Devel Ther. 2018;12:1281-92. https://doi.org/10.2147/DDDT.S159546.

42. Li S, Wang L, Yan X, Wang Q, Tao Y, Li J, Peng Y, Liu P, Liu C. Salvianolic acid $B$ attenuates rat hepatic fibrosis via downregulating angiotensin ii signaling. Evid Complement Alternat Med. 2012;2012:160726. https://doi. org/10.1155/2012/160726.

43. Jiang YF, Liu ZQ, Cui W, Zhang WT, Gong JP, Wang XM, Zhang Y, Yang MJ. Antioxidant effect of salvianolic acid B on hippocampal CA1 neurons in mice with cerebral ischemia and reperfusion injury. Chin J Integr Med. 2015;21(7):516-22. https://doi.org/10.1007/s11655-014-1791-1.

44. Cao YY, Wang L, Ge H, Lu XL, Pei Z, Gu Q, Xu J. Salvianolic acid A, a polyphenolic derivative from Salvia miltiorrhiza bunge, as a multifunctional agent for the treatment of Alzheimer's disease. Mol Divers. 2013;17(3):515-24. https://doi.org/10.1007/s11030-013-9452-z.

45. Hugel HM, Jackson N. Danshen diversity defeating dementia. Bioorg Med Chem Lett. 2014;24(3):708-16. https://doi.org/10.1016/j. bmcl.2013.12.042.

46. Guo Y, Li Y, Xue L, Severino RP, Gao S, Niu J, Qin LP, Zhang D, Bromme D. Salvia miltiorrhiza: an ancient Chinese herbal medicine as a source for anti-osteoporotic drugs. J Ethnopharmacol. 2014;155(3):1401-16. https:// doi.org/10.1016/j.jep.2014.07.058.

47. Cai H, Su S, Li Y, Zeng H, Zhu Z, Guo J, Zhu Y, Guo S, Yu L, Qian D, et al. Protective effects of Salvia miltiorrhiza on adenine-induced chronic renal failure by regulating the metabolic profiling and modulating the NADPH oxidase/ROS/ERK and TGF-beta/Smad signaling pathways. J Ethnopharmacol. 2018;212:153-65. https://doi.org/10.1016/j.jep.2017.09.021.
48. Cai HD, Su SL, Li Y, Zhu Z, Guo J, Zhu Y, Guo S, Qian D, Duan J. Simultaneous determination of four tanshinones by UPLC-TQ/MS and their pharmacokinetic application after administration of single ethanol extract of danshen combined with water extract in normal and adenine-induced chronic renal failure rats. Molecules. 2016;21:12. https://doi.org/10.3390/ molecules21121630.

49. Ahn YM, Kim SK, Lee SH, Ahn SY, Kang SW, Chung JH, Kim SD, Lee BC. Renoprotective effect of Tanshinone IIA, an active component of Salvia miltiorrhiza, on rats with chronic kidney disease. Phytother Res. 2010;24(12):1886-92. https://doi.org/10.1002/ptr.3347.

50. Jin Q, Jiang S, Wu YL, Bai T, Yang Y, Jin X, Lian LH, Nan JX. Hepatoprotective effect of cryptotanshinone from Salvia miltiorrhiza in D-galactosamine/ lipopolysaccharide-induced fulminant hepatic failure. Phytomedicine. 2014;21(2):141-7. https://doi.org/10.1016/j.phymed.2013.07.016.

51. Jiang Y, Zhang L, Rupasinghe HP. Antiproliferative effects of extracts from Salvia officinalis L. and Salvia miltiorrhiza Bunge on hepatocellular carcinoma cells. Biomed Pharmacother. 2017;85:57-67. https://doi. org/10.1016/j.biopha.2016.11.113.

52. Lemmon MA, Schlessinger J. Cell signaling by receptor tyrosine kinases. Cell. 2010;141(7):1117-34. https://doi.org/10.1016/j.cell.2010.06.011.

53. Jones S, Rappoport JZ. Interdependent epidermal growth factor receptor signalling and trafficking. Int J Biochem Cell Biol. 2014;51:23-8. https:// doi.org/10.1016/j.biocel.2014.03.014.

54. Tan C-S, Gilligan D, Pacey S. Treatment approaches for EGFR-inhibitorresistant patients with non-small-cell lung cancer. Lancet Oncol. 2015;16(9):e447-59. https://doi.org/10.1016/s1470-2045(15)00246-6.

55. Binder ZA, Thorne AH, Bakas S, Wileyto EP, Bilello M, Akbari H, Rathore S, Ha SM, Zhang L, Ferguson CJ, et al. Epidermal growth factor receptor extracellular domain mutations in glioblastoma present opportunities for clinical imaging and therapeutic development. Cancer Cell. 2018;34(1):163-77. https://doi.org/10.1016/j.ccell.2018.06.006.

56. Casadei Gardini A, Passardi A, Fornaro L, Rosetti P, Valgiusti M, Ruscelli S, Monti M, Casadei C, Pagan F, Frassineti GL. Treatment of squamous cell carcinoma of the anal canal: a new strategies with anti-EGFR therapy and immunotherapy. Crit Rev Oncol Hematol. 2018;123:52-6. https://doi. org/10.1016/j.critrevonc.2018.01.007.

57. Saloura V, Vokes EE. EGFR-based bioradiotherapy in SCCHN. Lancet Oncol. 2015;16(2):129-30. https://doi.org/10.1016/s1470-2045(15)70006-9.

58. Fuchs BC, Hoshida Y, Fujii T, Wei L, Yamada S, Lauwers GY, McGinn CM, DePeralta DK, Chen X, Kuroda T, et al. Epidermal growth factor receptor inhibition attenuates liver fibrosis and development of hepatocellular carcinoma. Hepatology. 2014;59(4):1577-90. https://doi.org/10.1002/ hep.26898.

59. Lanaya H, Natarajan A, Komposch K, Li L, Amberg N, Chen L, Wculek SK, Hammer M, Zenz R, Peck-Radosavljevic M, et al. EGFR has a tumourpromoting role in liver macrophages during hepatocellular carcinoma formation. Nat Cell Biol. 2014;16(10):972-7. https://doi.org/10.1038/ncb30 31.

60. Hwangbo W, Lee JH, Ahn S, Kim S, Park KH, Kim CH, Kim I. EGFR gene amplification and protein expression in invasive ductal carcinoma of the breast. Korean J Pathol. 2013;47(2):107-15. https://doi.org/10.4132/Korea nJPathol.

61. Kalman B, Szep E, Garzuly F, Post DE. Epidermal growth factor receptor as a therapeutic target in glioblastoma. Neuromol Med. 2013;15(2):420-34. https://doi.org/10.1007/s12017-013-8229-y.

62. Hennessy BT, Smith DL, Ram PT, Lu Y, Mills GB. Exploiting the PI3K/AKT pathway for cancer drug discovery. Nat Rev Drug Discov. 2005;4(12):9881004. https://doi.org/10.1038/nrd1902.

63. Porta C, Paglino C, Mosca A. Targeting PI3K/Akt/mTOR signaling in cancer. Front Oncol. 2014;4:64. https://doi.org/10.3389/fonc.2014.00064.

64. Huang WC, Hung MC. Induction of Akt activity by chemotherapy confers acquired resistance. J Formos Med Assoc. 2009;108(3):180-94. https://doi. org/10.1016/S0929-6646(09)60051-6.

65. Fruman DA, Rommel C. PI3K and cancer: lessons, challenges and opportunities. Nat Rev Drug Discov. 2014;13(2):140-56. https://doi.org/10.1038/ $\operatorname{nrd} 4204$.

66. Martini M, De Santis MC, Braccini L, Gulluni F, Hirsch E. PI3K/AKT signaling pathway and cancer: an updated review. Ann Med. 2014;46(6):372-83. https://doi.org/10.3109/07853890.2014.912836.

67. Perez-Ramirez C, Canadas-Garre M, Molina MA, Faus-Dader MJ, CallejaHernandez MA. PTEN and PI3K/AKT in non-small-cell lung cancer. 
Pharmacogenomics. 2015;16(16):1843-62. https://doi.org/10.2217/ pgs.15.122.

68. Lau MT, Leung PC. The PI3K/Akt/mTOR signaling pathway mediates insulin-like growth factor 1-induced E-cadherin down-regulation and cell proliferation in ovarian cancer cells. Cancer Lett. 2012;326(2):191-8. https ://doi.org/10.1016/j.canlet.2012.08.016.

69. Wei J, Wu J, Xu W, Nie H, Zhou R, Wang R, Liu Y, Tang G, Wu J. Salvanic acid B inhibits glycolysis in oral squamous cell carcinoma via targeting PI3K AKT/HIF-1alpha signaling pathway. Cell Death Dis. 2018;9(6):599. https:// doi.org/10.1038/s41419-018-0623-9.

70. Ke F, Wang Z, Song X, Ma Q, Hu Y, Jiang L, Zhang Y, Liu Y, Zhang Y, Gong W. Cryptotanshinone induces cell cycle arrest and apoptosis through the
JAK2/STAT3 and PI3K/Akt/NFkappaB pathways in cholangiocarcinoma cells. Drug Des Devel Ther. 2017;11:1753-66. https://doi.org/10.2147/ DDDT.S132488.

71. Qiu Y, Li C, Wang Q, Zeng X, Ji P. Tanshinone IIA induces cell death via Beclin-1-dependent autophagy in oral squamous cell carcinoma SCC-9 cell line. Cancer Med. 2018;7(2):397-407. https://doi.org/10.1002/ cam4.1281.

\section{Publisher's Note}

Springer Nature remains neutral with regard to jurisdictional claims in published maps and institutional affiliations.
Ready to submit your research? Choose BMC and benefit from:

- fast, convenient online submission

- thorough peer review by experienced researchers in your field

- rapid publication on acceptance

- support for research data, including large and complex data types

- gold Open Access which fosters wider collaboration and increased citations

- maximum visibility for your research: over $100 \mathrm{M}$ website views per year

At BMC, research is always in progress.

Learn more biomedcentral.com/submissions 